\title{
A Platinum molecular complex immobilised on the surface of graphene as active catalyst in alkyne hydrosilylation
}

\author{
Andres Mollar-Cuni, ${ }^{[a]}$ Pilar Borja, ${ }^{[a]}$ Santiago Martin, ${ }^{[b]}$ Gregorio Guisado-Barrios, ${ }^{[a]}$ and Jose A. Mata ${ }^{*[a]}$
}

[a] A. Mollar-Cuni, Dr. P. Borja, Dr. G. Guisado-Barrios and Dr. J. A. Mata

Institute of Advanced Materials (INAM), Centro de Innovación en Química Avanzada (ORFEO-CINCA)

Universitat Jaume I

Avda. Sos Baynat s/n, 12006, Castellón, Spain

E-mail: imata@uji.es

http://www.inam.uji.es/research-divisions/research-division-dr-jose-mata

[b] Dr. S. Martin

Departamento de Química Física (Facultad de Ciencias), Instituto de Ciencias de Materiales de Aragón (ICMA)

Universidad de Zaragoza-CSIC

C/Pedro Cerbuna 1250009 Zaragoza, Spain

Supporting information for this article is given via a link at the end of the document.

\begin{abstract}
A platinum complex bearing a $\mathrm{N}$-heterocyclic carbene $(\mathrm{NHC})$ ligand functionalised with a pyrene-tag is immobilised onto the surface of reduced graphene oxide ( $\mathrm{rGO}$ ). The hybrid material composed of an organometallic complex and a graphene derivative is ready available in a single-step process under mild reaction conditions. This methodology preserves the inherent properties of the active catalytic centre and the support. The platinum hybrid material is an efficient catalyst in hydrosilylation of alkynes and can be recycled and reused without significant loss of activity due to its high stability. Interestingly, the catalytic activity of the platinum complex is not affected by diffusion problems after immobilisation. The influence of graphene in hydrosilylation of alkynes is discussed in terms of activity and selectivity.
\end{abstract}

\section{Introduction}

Hydrosilylation of alkynes represents a direct approach for the synthesis of carbon-silicon bonds. ${ }^{[1-4]}$ These compounds are useful industrial intermediates for the production of fine chemicals silicones, lubricants, coatings and fine chemicals. ${ }^{[5][6]}$ Among all the metals active in hydrosilylation reactions, platinum stands out in terms of activity and selectivity. As example, highly active Karstedt ${ }^{[7]}$ and Speier ${ }^{[8]}$ catalysts, are present in several industrial processes (Fig. 1). However, they bear limited stability against oxygen and moisture under catalytic conditions forming platinum species that can taint the products. In order to circumvent this problem, Markó et al, introduced a series of $\mathrm{N}$-heterocyclic carbene ligand (NHC) based platinum complexes (Fig. 1) ${ }^{[9-12]}$ These homogeneous catalysts have shown remarkable efficiency and selectivity in the hydrosilylation of alkynes under aerobic conditions but they cannot be easily isolated and used in multiple runs. ${ }^{[13-18]}$ Hence, seeking new effective alternatives for catalysts endurance is highly encouraging. In this context, immobilisation of molecular metal complexes onto supports enables the development of hybrid materials with specific and controllable properties relevant for ulterior catalytic applications. ${ }^{[19-22]}$ Metal complexes can be anchored onto supports by means of strong covalent bonds in order to avoid leaching during the catalytic reactions. This immobilisation process normally requires several synthetic steps and lacks of a complete control in the way the metal sites are tethered to supports. ${ }^{[23-25]}$ Some of them have recently been applied for the hydrosilylation of terminal alkynes. ${ }^{[26-28]}$ On the contrary, the use of non-covalent interaction for the immobilisation of well-defined complexes onto graphene allows the preparation of hybrid materials in a single step with controllable metal positions at specific sites. ${ }^{[29-32]}$ This approach is complementary to homogeneous systems, since allows the easy recovery of the catalysts, and at the same time provides mechanistic information regarding catalysts resting state. In addition, the immobilisation of metal complexes facilitates the precise control of the catalytic active sites. ${ }^{[33-35]}$ Based on our experience on the preparation of different supported catalysts, we envisioned that the incorporation of a molecular platinum catalyst onto the surface of graphene could result beneficial for the hydrosilylation reaction of alkynes by: i) decreasing the kinetics of the deactivation pathways, ii) hampering the interaction with external agents and iii) increasing the catalyst activity by facilitating the interactions between the catalyst and the substrates.

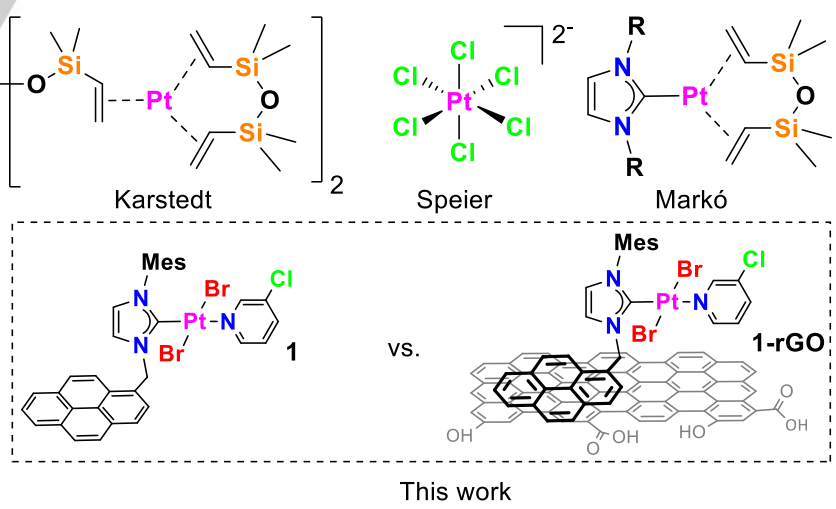

Figure 1. Active platinum catalytic systems for hydrosilylation.

Herein, in this manuscript, we describe a contrastive study of the structural and catalytic properties of a molecular platinum type PEPPSI complex 1 (PEPPSI = pyridine-enhanced precatalyst preparation, stabilisation and initiation) and its related derivative immobilised onto the surface of reduced graphene oxide (rGO) by non-covalent interactions 1-rGo (Fig.1). The hybrid catalytic material is obtained in a single step starting from an organometallic complex and the carbonaceous material. 


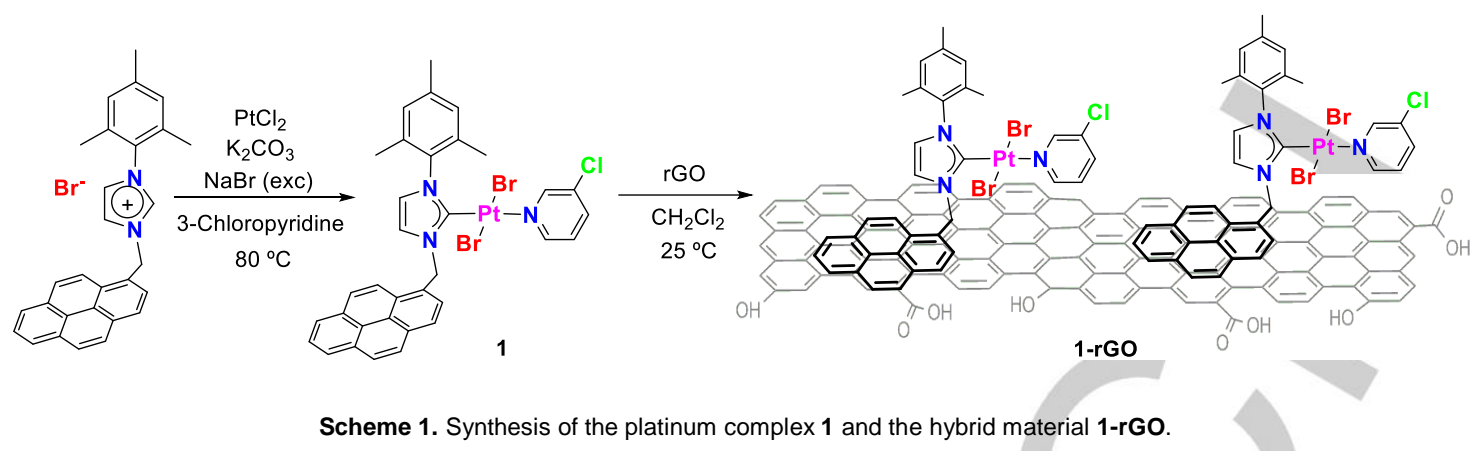

The catalytic performance of both, molecular system and the hybrid material were evaluated towards the hydrosilylation reaction of alkynes. Metal complex $\mathbf{1}$ is a competent catalyst towards terminal and internal alkynes displaying moderate regioselectivity, having a preferential inclination for $\beta$ versus the $\alpha$ isomer. In parallel, the catalytic activity of 1 was matched by the hybrid material 1-rGO, which displayed a greater stability but present the advantage that can be recycled and reused for up to ten runs without significant loss of activity.

\section{Results and Discussion}

The platinum molecular complex 1 and the related hybrid material 1-rGO immobilized onto graphene were synthesised as described in Scheme 1. The aim of this study is the evaluation of the catalytic properties in hydrosilylation from a homogeneous and heterogeneous approach. Initially, molecular Pt-NHC complex 1 was prepared by applying the same methodology described for the palladium PEPPSI type complexes. ${ }^{[36-38]}$ Imidazolium salt functionalised with a pyrene polyaromatic tag ${ }^{[39]}$ used as ligand precursor was treated with $\mathrm{PtCl}_{2}$, 3-chloropyridine, $\mathrm{K}_{2} \mathrm{CO}_{3}$ as based and excess of $\mathrm{NaBr}$ to avoid halide scrambling. Complex 1 was isolated in $70 \%$ yield and fully characterised by NMR spectroscopy, ESI-MS spectrometry, elemental analysis and thermogravimetric analysis. The complete characterisation at the molecular level facilitates the monitoring of the changes that the complex undergoes during the immobilisation process and the catalytic experiments. Coordination of the NHC ligand to platinum is confirmed by the disappearance of the acidic signal in ${ }^{1} \mathrm{H}$ NMR spectra of the imidazolium salt at $9.36 \mathrm{ppm} .{ }^{13} \mathrm{C}$ NMR spectra showed the characteristic signal for $\mathrm{Pt}-\mathrm{C}_{\text {carbene }}$ at $148.3 \mathrm{ppm}$ although the satellites corresponding to the coupling with ${ }^{195} \mathrm{Pt}$ are not observed due to their low intensity. Positive ion ESI mass spectrum analysis (ESI-MS) in acetonitrile of complex 1 shows a base peak for $\left[\mathrm{M}-\mathrm{Br}+\mathrm{CH}_{3} \mathrm{CN}\right]^{+}$at $m / z=830.3$ and a less intense peak for $\left[\mathrm{M}-\mathrm{Br}-(3-\mathrm{Cl}-\mathrm{Pyridine})+2 \mathrm{CH}_{3} \mathrm{CN}\right]^{+}$at $\mathrm{m} / \mathrm{z}=757.3$. The presence of these fragments confirms the proposed molecular composition of complex 1 based on the mass/charge relation and the isotopic pattern. In addition, it reveals the lability of the 3chloropyridine ligand, as expected for PEPPSI-type complexes. Metal-halide bond-breaking is a common ionisation mechanism for neutral complexes under ESI conditions and L-type ligands correlate with ease metal-ligand substitution. The molecular structure of complex 1 was confirmed by single-crystal X-ray diffraction. ${ }^{[40]}$ The structure analysis reveals a platinum centre with two trans bromides, a 3-chloropyridine and the NHC ligand in square-planar coordination environment (Fig. 2).

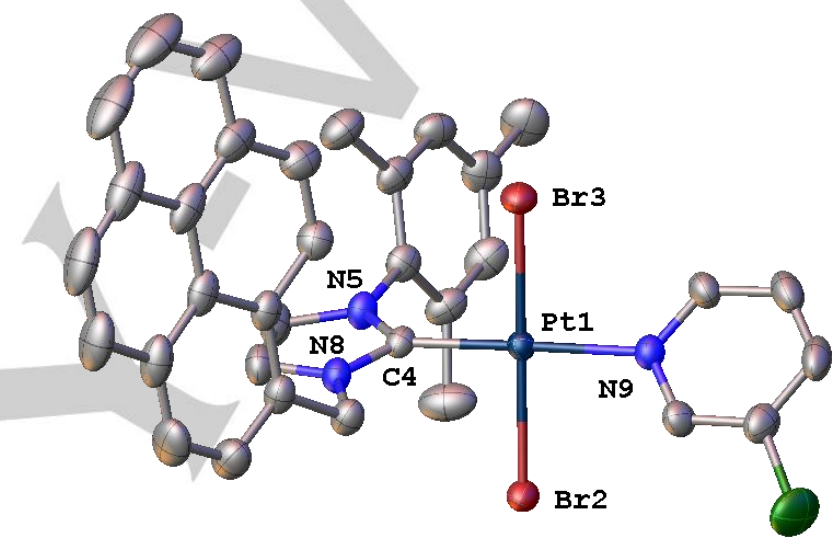

Figure 2. Molecular structure of compound 1. Ellipsoids are at $50 \%$ probability level. Hydrogen atoms and crystallisation solvent (dichloromethane) have been omitted for clarity. Selected bond lengths $[\AA]$ and angles [ $\left.{ }^{\circ}\right]: \operatorname{Pt}(1)-C(4) 1.962(3)$, $\mathrm{Pt}(1)-\operatorname{Br}(2)$ 2.4266(3), $\mathrm{Pt}(1)-\mathrm{Br}(3)$ 2.4173(4), $\mathrm{Pt}(1)-\mathrm{N}(9)$ 2.097(3), $\mathrm{Br}(2)-\mathrm{Pt}(1)$ - $\mathrm{Br}(3)$ 176.945(13), N(9) - Pt(1) - C(4) 178.55(12), N(9) - Pt(1) - $\operatorname{Br}(2)$ 89.76(8), $\mathrm{C}(4)-\operatorname{Pt}(1)-\operatorname{Br}(2) 89.37(9)$.

The hybrid organometallic-graphene material 1-rGo was obtained by applying an immobilisation methodology previously reported by us. ${ }^{[30,41,42]}$ It is based in the establishment of noncovalent $\pi$-type interactions between the polyaromatic pyrene tag and the rGO. The tethering of the molecular complex involves mixing complex 1 with reduced graphene oxide ( $\mathrm{rGO}$ ) in dichloromethane at room temperature, followed by 30 minutes sonication in a water bath. Finally, the mixture is stirred at room temperature for $24 \mathrm{~h}$. The exact platinum content on the hybrid material 1-rGO was determined by digestion of the samples in hot mixture of $\mathrm{HCl} / \mathrm{HNO}_{3}$ followed by ICP-MS analysis. The results obtained by ICP-MS analysis accounted for 4.6 wt $\%$ of 1 in the hybrid material 1-rGo.

The characterisation of the platinum hybrid material 1-rGo was performed using High Resolution Transmission Microscopy (HRTEM) and X-ray Photoelectron Spectroscopy (XPS). HRTEM images of 1-rGO at different magnifications (Fig. 3a,b) show the characteristic 2D morphology of graphene and the absence of metal nanoparticles. Elemental mapping by Energy-Dispersive $X$ ray Spectroscopic analysis (EDS) of 1-rGO (Fig. 3c) confirms the elemental composition of the molecular complex $1(\mathrm{Pt}, \mathrm{N}, \mathrm{Br}$ and 
$\mathrm{Cl}$ ) and the homogeneous distribution of platinum in the hybrid materials (Fig. $3 d$ ). In parallel to this, the surface of hybrid material 1-rGO, was characterised and analysed by means of XPS. This technique provides relevant information related to the elemental composition and oxidation states. In our case, a comparative analysis of complex $\mathbf{1}$ and hybrid material 1-rGo facilitates the interpretation of the results. A survey XPS analysis of 1 shows the presence of platinum, nitrogen, bromide and chloride (Fig. 4). As expected for the molecular complex 1, the two peaks of Pt4f confirm the +2 oxidation state at binding energies of 72.7 and 76.0 $\mathrm{eV} .{ }^{[43]} \mathrm{A}$ high-resolution XPS analysis of $\mathbf{1}$ and $\mathbf{1}-\mathrm{rGO}$ shows the characteristic core-level peaks of $\mathrm{P} 44 \mathrm{f}, \mathrm{Br} 3 \mathrm{~d}, \mathrm{~N}$ 1s and $\mathrm{Cl} 2 \mathrm{p}$ at the same binding energies for the molecular complex and the hybrid material (Fig. 4). These results confirm the tethering of the molecular complex 1 onto the surface of graphene. The nature of the complex is not altered during the harness process. Additionally, we have evidence of the exact nature and composition of the platinum species deposited onto the graphene surface.
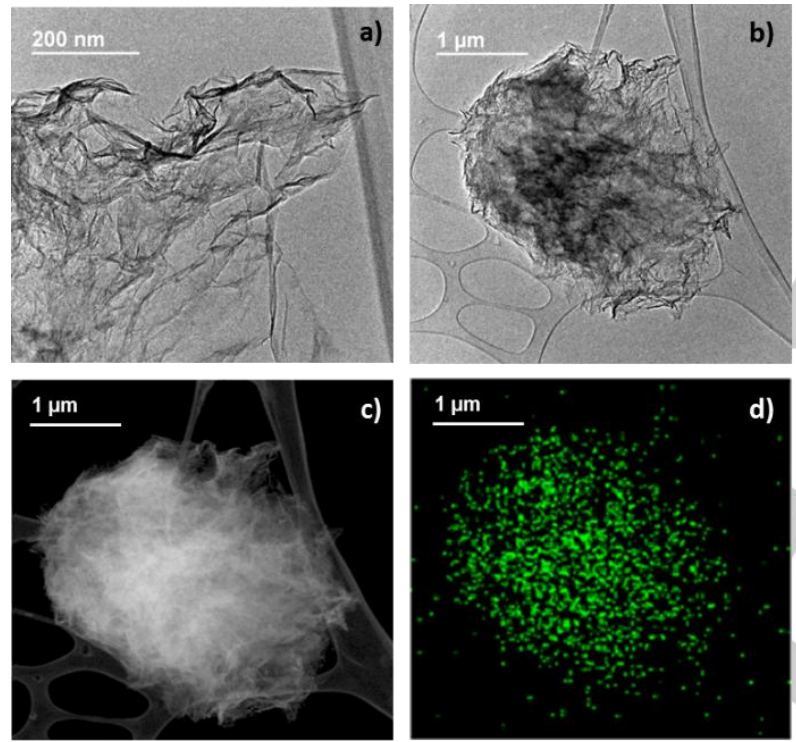

Figure 3. HRTEM images of 1-rGO at different magnifications (a,b). STEM images (c) and EDS elemental mapping (d) images showing the homogeneous distribution of platinum on the hybrid material 1-rGO.

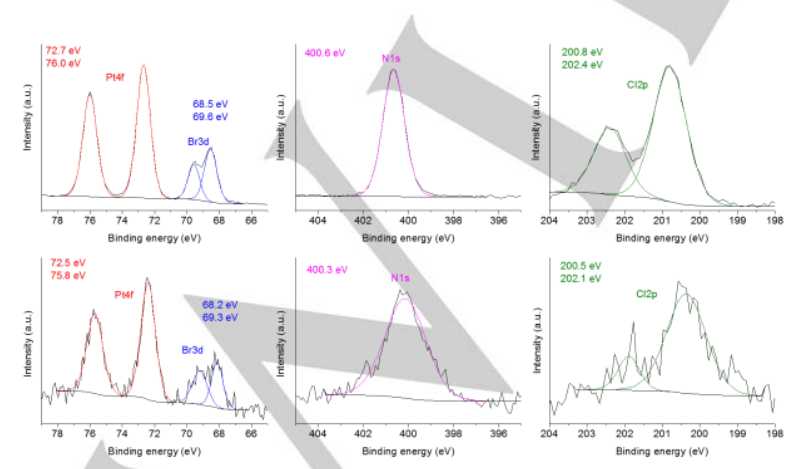

Figure 4. XPS analysis of the core-level peaks $\mathrm{Pt} 4 \mathrm{f}, \mathrm{Br} 3 \mathrm{~d} \mathrm{~N} 1 \mathrm{~s}$ and $\mathrm{Cl} 2 \mathrm{p}$ for complex 1 (top) and hybrid material 1-rGO (bottom).

\section{Catalytic applications}

The catalytic properties of the molecular platinum complex 1 and the hybrid material 1-rGO were studied in the hydrosilylation reaction of internal and terminal alkynes. Optimisation of reaction conditions was carried out using phenyl acetylene and dimethylphenylsilane as model substrates (Table 1).

Table 1. Optimisation of reaction conditions for the hydrosilylation of phenyl acetylene.

\begin{tabular}{|c|c|c|c|c|c|c|}
\hline Entry & $\begin{array}{l}\text { Cat. } \\
\text { mol\% }\end{array}$ & $\begin{array}{c}\text { Solvent } \\
(1 \mathrm{~mL}) \\
\end{array}$ & $\begin{array}{c}\mathrm{T} \\
\left({ }^{\circ} \mathrm{C}\right) \\
\end{array}$ & $\begin{array}{c}\text { Time } \\
\text { (h) }\end{array}$ & $\begin{array}{l}\text { Conv } \\
(\%)^{[a]} \\
\end{array}$ & $\begin{array}{l}\text { Sel.[a] } \\
(\alpha / \beta)\end{array}$ \\
\hline 1 & - & Toluene & 50 & 3 & 0 & - \\
\hline 2 & - & Toluene & 80 & 3 & 0 & - \\
\hline 3 & 1 & Toluene & 30 & 3 & 0 & - \\
\hline 4 & 1 & Toluene & 50 & 3 & 0 & - \\
\hline 5 & 1 & Toluene & 65 & 3 & 5 & $30 / 70$ \\
\hline 6 & 1 & Toluene & 80 & 3 & 40 & $33 / 67$ \\
\hline 7 & 1 & Toluene & 90 & 3 & 76 & $32 / 68$ \\
\hline 8 & $1^{b}$ & Toluene & 80 & 3 & 29 & $33 / 67$ \\
\hline 9 & 0.5 & Toluene & 80 & 3 & 34 & $32 / 68$ \\
\hline 10 & 0.5 & Toluene & 80 & 6.5 & 69 & $35 / 65$ \\
\hline 11 & 0.5 & Toluene & 80 & 24 & $\geqslant 99$ & $32 / 68$ \\
\hline 12 & 0.5 & $\mathrm{MeCN}$ & 80 & 3 & 8 & $40 / 60$ \\
\hline 13 & 0.5 & Dioxane & 80 & 3 & 74 & $41 / 59$ \\
\hline 14 & 0.5 & Dichloroethane & 80 & 3 & 10 & $40 / 60$ \\
\hline
\end{tabular}

Conditions: $0.3 \mathrm{mmol}$ of alkyne, $0.31 \mathrm{mmol}$ of silane and $0.3 \mathrm{mmol}$ of anisole used as internal standard. Aerobic conditions. [a] conversion of alkyne and selectivity determined by $\mathrm{GC}$ analyses. [b] $\mathrm{KPF}_{6}$ (3 mol\%) was used as additive.

Control experiments at two different temperatures 50 and $80{ }^{\circ} \mathrm{C}$ respectively were carried out to confirm that the metal complex is required in the hydrosilylation reaction. No conversion was observed when the reaction was performed in the absence of the platinum catalyst 1 (Table 1 , entry 1,2 ). Then, we evaluated the activity of the catalyst varying the temperature (Table 1 , entries 3 - 7). Using $1 \mathrm{~mol} \%$ of catalyst, the reaction does not occur below $50{ }^{\circ} \mathrm{C}$ and it is very slow at $65^{\circ} \mathrm{C}(3 \mathrm{~h}, 5 \%$ yield $)$. Increasing the temperature to $80-90 \stackrel{\circ}{\circ}$ affords moderate to good conversions after $3 \mathrm{~h}$. According to these results, the lowest temperature to study the hydrosilylation reaction under reasonable experimental conditions was $80^{\circ} \mathrm{C}$. The addition of a halide abstractor $\left(\mathrm{KPF}_{6}\right)$ did not improve the catalytic outcomes (Table 1, entry 8). Reduction of catalyst loading to $0.5 \mathrm{~mol} \%$ allows to monitor the reaction into a reasonable time-scale of $24 \mathrm{~h}$ (Table 1, entries 9 11). The influence of catalyst loading in hydrosilylation is described using reaction progress profiles in the supporting information (Figure S16). We evaluated the solvent influence and observed that hydrosilylation also took place with solvents other than toluene such as $\mathrm{MeCN}$, dioxane and dichloroethane (Table 1 , entries 12 - 14). It is worth mentioning that although higher activity was observed when using dioxane, lower selectivity was obtained (Entry 13). The influence of the presence of air or moisture was assessed. No significant catalytic difference in the presence of air was observed, suggesting a relative high stability of catalysts precursor and intermediates versus oxygen. The optimal results in terms of activity and selectivity for the study of 
hydrosilylation reaction were obtained using a catalyst loading of $0.5 \mathrm{~mol} \%$, toluene as solvent at $80^{\circ} \mathrm{C}$ under aerobic conditions. Next, we studied the scope and limitations in hydrosilylation of different terminal and internal alkynes under these reaction conditions.

Table 2. Hydrosilylation of terminal alkynes.

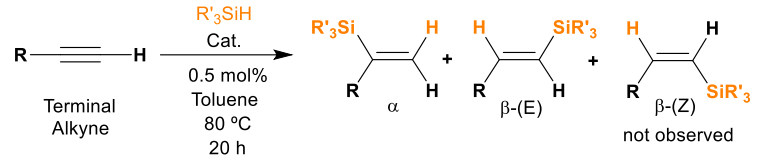

\begin{tabular}{cccccc}
\hline Entry & $\mathbf{R}$ & $\mathbf{R}_{3}{ }_{3} \mathrm{SiH}$ & Cat. & $\begin{array}{c}\text { Yields } \\
(\%)^{[a]}\end{array}$ & $\begin{array}{c}\text { Sel. }(\%)^{[a]} \\
\alpha / \beta(\mathrm{E}) / \beta(\mathrm{Z})\end{array}$ \\
\hline 1 & $\mathrm{Ph}$ & $\mathrm{Me}_{2} \mathrm{PhSiH}$ & $\mathbf{1}$ & 91 & $35 / 65 / 0$ \\
2 & $\mathrm{Ph}$ & $\mathrm{Me}_{2} \mathrm{PhSiH}$ & $\mathbf{1 - r G o}$ & 96 & $43 / 57 / 0$ \\
3 & $\mathrm{Ph}$ & $\mathrm{Et}{ }_{3} \mathrm{SiH}$ & $\mathbf{1}$ & 94 & $65 / 35 / 0$ \\
4 & $p$-tolyl & $\mathrm{Me}_{2} \mathrm{PhSiH}$ & $\mathbf{1}$ & 80 & $30 / 70 / 0$ \\
5 & $p$-tolyl & $\mathrm{Et}_{3} \mathrm{SiH}$ & $\mathbf{1}$ & 92 & $65 / 35 / 0$ \\
6 & Benzyl & $\mathrm{Me}_{2} \mathrm{PhSiH}$ & $\mathbf{1}$ & $\geqslant 99$ & $40 / 60 / 0$ \\
7 & Benzyl & $\mathrm{Me}_{2} \mathrm{PhSiH}$ & $\mathbf{1 - r G O}$ & $\geqslant 99$ & $32 / 68 / 0$ \\
8 & $\mathrm{Benzyl}$ & $\mathrm{Et}_{3} \mathrm{SiH}$ & $\mathbf{1}$ & 93 & $42 / 58 / 0$ \\
9 & $n$-Hex & $\mathrm{Me}_{2} \mathrm{PhSiH}$ & $\mathbf{1}$ & 94 & $30 / 70 / 0$ \\
10 & $n-\mathrm{Hex}$ & $\mathrm{Me}_{2} \mathrm{PhSiH}$ & $\mathbf{1 - r G O}$ & 94 & $25 / 75 / 0$ \\
11 & $n-\mathrm{Hex}$ & $\mathrm{Et}_{3} \mathrm{SiH}$ & $\mathbf{1}$ & $\geqslant 99$ & $38 / 62 / 0$ \\
12 & $\left(\mathrm{CH}_{2}\right)_{3} \mathrm{CN}$ & $\mathrm{Me}_{2} \mathrm{PhSiH}$ & $\mathbf{1}$ & 82 & $37 / 63 / 0$ \\
13 & $\left(\mathrm{CH}_{2}\right)_{3} \mathrm{CN}$ & $\mathrm{Me}_{2} \mathrm{PhSiH}$ & $\mathbf{1 - r G O}$ & 90 & $39 / 61 / 0$ \\
14 & $\left(\mathrm{CH}_{2}\right)_{3} \mathrm{CN}$ & $\mathrm{Et}_{3} \mathrm{SiH}$ & $\mathbf{1}$ & 87 & $35 / 65 / 0$ \\
\hline
\end{tabular}

Reaction conditions: $0.3 \mathrm{mmol}$ of alkyne, $0.31 \mathrm{mmol}$ of silane, $0.5 \mathrm{~mol} \%$ of catalyst (based on $\mathrm{Pt}$ ), $\mathrm{T}=80^{\circ} \mathrm{C}, 20 \mathrm{~h}$ and $1 \mathrm{~mL}$ of toluene. Aerobic conditions. [a] Yields were determined with GC using anisole as a standard and selectivity by ${ }^{1} \mathrm{H}$ NMR.

We first explored the hydrosilylation of aryl (Table 2, entry 1-5) and alkyl terminal alkynes (Table 2, entry 6-14) using complex 1 and the hybrid material 1-rGO. Both catalytic systems are competent in the hydrosilylation of alkynes affording quantitative yields after $20 \mathrm{~h}$ reaction. Preliminary comparison experiments of 1 vs. 1-rGO for different substrates reveal that the catalytic activity is maintain or slightly improved (Vide infra). We have observed that substrate scope is maintained after immobilization (Table 2, entries $2,7,10,13$ ). Improvement of $\alpha / \beta$ regioselectivity is a difficult task in hydrosilylation. In our case, we have observed that the average regioselectivy is $40 / 60$ for the $\alpha / \beta$-addition products (Table 2). We have observed that regioslectivity is maintained after catalysts immobilization. The best results were obtained in the case of 1 -hexyne displaying a regioselectivity ratio of $25 / 75$ for the $\alpha / \beta$-addition products using catalysts 1 -rGO (Table 2 , entry $10)$. Interestingly a very high stereoselectivity towards the $\beta(\mathrm{E})$ versus the $\beta(Z)$-addition product was observed. In fact, no formation of $\beta(Z)$-isomer was detected in any case.

Then, we studied the performance of complex 1 and the hybrid material 1-rGO in hydrosilylation of a variety of internal alkynes using different silanes (Table 3), resulting an efficient catalysts. Yields over $90 \%$ were obtained for internal alkynes in ca. $3 \mathrm{~h}$, much faster than the previously observed for the terminal alkynes. The regioselectivity for non-symmetric internal alkynes favors the addition of the silyl group at the $C$ atom bound next to the phenyl group (defined as the $\alpha$-addition product). We have observed that the regioselectivity is controlled by sterics imposed by the alkyne rather than the nature of the silane. For instance, the hydrosilylation of the small ethyl phenyl acetylene gave moderate selectivities (Table 3, entries $1-2$ ). In contrast, when using a more steric demanding trimethylsilane phenyl acetylene the regioselectivity was $100 \%$ and only the $\alpha$ isomer was observed (Table 3, entries $5-7$ ). These results suggest that steric factors of the internal alkyne dominate the selectivity of the reaction.

Table 3. Hydrosilylation of internal alkynes.

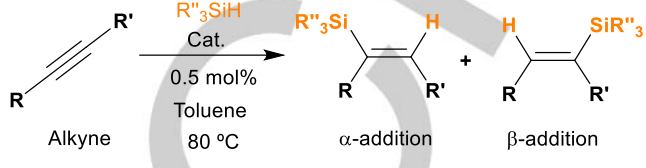

\begin{tabular}{|c|c|c|c|c|c|c|c|}
\hline Entry & $\mathbf{R}$ & $\mathbf{R}^{\prime}$ & R"' ${ }_{3} \mathrm{SiH}$ & Cat. & $\mathbf{t}(\mathrm{h})$ & $\begin{array}{l}\text { Yield } \\
(\%)^{[a]}\end{array}$ & $\begin{array}{c}\text { Sel. } \\
(\%)^{[a]} \\
(\alpha / \beta)\end{array}$ \\
\hline 1 & $\mathrm{Ph}$ & Et & $\mathrm{Me}_{2} \mathrm{PhSiH}$ & 1 & 2.5 & 99 & $82 / 18$ \\
\hline 2 & $\mathrm{Ph}$ & Et & $\mathrm{Et}_{3} \mathrm{SiH}$ & 1 & 4 & $\geqslant 99$ & $81 / 19$ \\
\hline 3 & $\mathrm{Ph}$ & $\mathrm{nPr}$ & $\mathrm{Me}_{2} \mathrm{PhSiH}$ & 1 & 2 & 93 & $84 / 16$ \\
\hline 4 & $\mathrm{Ph}$ & $\mathrm{nPr}$ & $\mathrm{Et}_{3} \mathrm{SiH}$ & 1 & 3 & $\geqslant 99$ & $79 / 21$ \\
\hline 5 & $\mathrm{Ph}$ & $\left(\mathrm{CH}_{3}\right)_{3} \mathrm{Si}$ & $\mathrm{Me} 2 \mathrm{PhSiH}$ & 1 & 2.5 & 86 & $100 / 0$ \\
\hline 6 & $\mathrm{Ph}$ & $\left(\mathrm{CH}_{3}\right)_{3} \mathrm{Si}$ & $\mathrm{Me}_{2} \mathrm{PhSiH}$ & 1-rGo & 2.5 & 87 & $100 / 0$ \\
\hline 7 & $\mathrm{Ph}$ & $\left(\mathrm{CH}_{3}\right)_{3} \mathrm{Si}$ & $\mathrm{Et}_{3} \mathrm{SiH}$ & 1 & 6 & 96 & $100 / 0$ \\
\hline 8 & $\mathrm{Ph}$ & $\mathrm{Ph}$ & $\mathrm{Me}_{2} \mathrm{PhSiH}$ & 1 & 1 & $\geqslant 99$ & $-b$ \\
\hline 9 & $\mathrm{Ph}$ & $\mathrm{Ph}$ & $\mathrm{Et}_{3} \mathrm{SiH}$ & 1 & 6 & 92 & $-b$ \\
\hline 10 & $\mathrm{nPr}$ & $\mathrm{nPr}$ & $\mathrm{Me}_{2} \mathrm{PhSiH}$ & 1 & 1.5 & $\geqslant 99$ & $-b$ \\
\hline 11 & $\mathrm{nPr}$ & $\mathrm{nPr}$ & $\mathrm{Me}_{2} \mathrm{PhSiH}$ & 1-rGo & 1.5 & $\geqslant 99$ & $-b$ \\
\hline 12 & $\mathrm{nPr}$ & $\mathrm{nPr}$ & $\mathrm{Et}_{3} \mathrm{SiH}$ & 1 & 3.5 & 95 & $-b$ \\
\hline 13 & $\mathrm{MeO}\left(\mathrm{CH}_{2}\right)_{2}$ & $\mathrm{MeO}\left(\mathrm{CH}_{2}\right)_{2}$ & $\mathrm{Me}_{2} \mathrm{PhSiH}$ & 1 & 4 & 92 & $-b$ \\
\hline 14 & $\mathrm{MeO}\left(\mathrm{CH}_{2}\right)_{2}$ & $\mathrm{MeO}\left(\mathrm{CH}_{2}\right)_{2}$ & $\mathrm{Me}_{2} \mathrm{PhSiH}$ & 1-rGo & 3 & 95 & $-b$ \\
\hline 15 & $\mathrm{MeO}\left(\mathrm{CH}_{2}\right)_{2}$ & $\mathrm{MeO}\left(\mathrm{CH}_{2}\right)_{2}$ & $\mathrm{Et}_{3} \mathrm{SiH}$ & 1 & 6 & 98 & $-b$ \\
\hline
\end{tabular}

Regioselectivity $(\alpha / \beta)$ vs. the $\mathrm{Ph}$ group except for symmetric alkynes. $E / Z$ isomerism not determined. Reaction conditions: $0.3 \mathrm{mmol}$ of alkyne, $0.31 \mathrm{mmol}$ of silane, $0.5 \mathrm{~mol} \%$ of catalyst, $\mathrm{T}=80^{\circ} \mathrm{C}$ and $1 \mathrm{~mL}$ of toluene. Aerobic conditions. [a] Yields were determined with GC using anisole as a standard and selectivity by ${ }^{1} \mathrm{H}$ NMR. [b] Only one regioisomer is possible.

Next, different competition experiments were carried out to explore the selectivity of alkyne hydrosilylation in the presence of other substrates bearing different functional groups such as alkenes, aldehydes, and nitriles (Fig. S13 - S15). It was found that the platinum catalyst $\mathbf{1}$ produced the hydrosilylation of alkynes without altering any of the other substrates bearing aldehydes, alkenes or nitriles. It is important to note that the kinetics of hydrosilylation are strongly affected by the presence of other functionalities and in particular the induction time is completely different. The results suggest that complex $\mathbf{1}$ is a competent catalyst in the hydrosilylation of alkynes also in the presence of other functional groups.

We assessed the effect of catalyst loading in the hydrosilylation of 1-phenyl-1-butyne with dimethylphenylsilane using 1 (Fig. S16). The reaction progress profiles showed that quantitative yields are obtained for catalyst loadings between 2 $0.01 \mathrm{~mol} \%$. These experiments reveal that the induction time is dependent of the catalyst loading. The maximum catalyst turnover number (TON) of $9.3 \times 10^{3}$ was obtained at 0.01 mol\% loading after $24 \mathrm{~h}$. The best catalyst turnover frequency (TOF) at $50 \%$ conversion reached a remarkable $380 \mathrm{~h}^{-1}$ and was achieved when using a catalyst loading of $0.01 \mathrm{~mol} \%$. These results reveal that 1 is a robust and stable catalyst. In order to analyse the nature of the catalytic active species we performed poisoning experiments (ESI). We used poly(4-vinylpyridine) $(P V P)^{[44]}$ as an scavenger of 
$\mathrm{Pt}(\mathrm{II})$ molecular species and $\mathrm{Hg}$ (Mercury test) ${ }^{[45]}$ as an scavenger of Pt nanoparticles. ${ }^{[46]}$ The addition of $\mathrm{Hg}$ increases the time of the induction period from 50 to ca. 100 min (Compare Fig. S12 vs S17). The results reveal that the addition of mercury had no effect in hydrosilylation but the addition of PVP completely inhibits the reaction (Fig. S17). The poisoning experiments suggest that the catalytic active species are homogeneous in nature.

Once we studied the reaction scope and limitations of complex 1 and the hybrid material 1-rGO, we explored the catalytic properties of both systems by means of reaction progress profiles in the hydrosilylation of phenyl acetylene (Fig. 5). These experiments provide valuable information of apparent reaction rates, induction time and influence of the support in the catalytic reaction. Both reactions were carried out under the exact conditions and using the same catalyst loading ( $0.5 \mathrm{~mol} \%)$. The reaction progress profiles reveal that the supported catalyst is more active that the molecular version in terms of reaction rates (TOF) and product formation (TON). For instance, the yield is ca. $80 \%$ for the hybrid material $1-r G O$ and $56 \%$ for the molecular complex 1 after $5 \mathrm{~h}$. Importantly, immobilization of 1 onto graphene aided to reduce the induction period significantly as show in the reaction profile (Fig. 5). These results indicate that the activity of catalyst $\mathbf{1}$ is not affected by diffusion problems when supported onto graphene. In general, diffusion problems are especially important when using supported catalysts onto porous materials. The 2D structure of graphene avoids or at least limits the problems related to diffusion issues. We have observed that this process is general and it has been experienced for other catalytic systems using graphene as support. ${ }^{[47-53]}$ The catalytic activity of the molecular platinum complex improves when supported onto graphene.

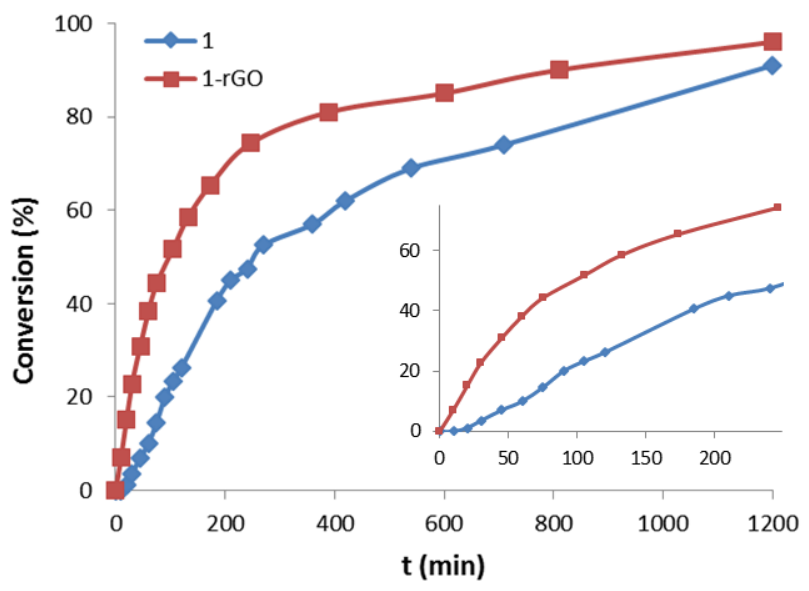

Figure 5. Reaction progress profile in the hydrosilylation of phenylacetylene using catalysts 1 and 1-rGO. Reaction conditions: $0.3 \mathrm{mmol}$ of phenylacetylene, $0.31 \mathrm{mmol}$ of $\mathrm{PhMe} 2 \mathrm{SiH}, 0.5 \mathrm{~mol} \%$ of catalyst (based on $\mathrm{Pt}$ ), $\mathrm{T}=80^{\circ} \mathrm{C}$ and 1 $\mathrm{mL}$ of toluene. Conversion by $\mathrm{GC}$ analysis using anisole as a standard.

A common problem generally encountered in supported catalysis is the release of the catalytic active species into the solution during the reaction, known as the "boomerang effect". ${ }^{[54,55]}$ In order to evaluate the mechanism of action in the immobilisation of molecular species onto graphene we performed hot filtration experiments. ${ }^{[56]}$ We used catalyst 1-rGO $(0.5 \mathrm{~mol} \%)$ in the hydrosilylation of phenylacetylene and dimethylphenylsilane as a model reaction. After $2 \mathrm{~h}$ reaction (GC conversion $54 \%$ ), half of the reaction mixture was separated by filtration at $80^{\circ} \mathrm{C}$. The GC analysis after $15 \mathrm{~h}$ indicates a slight increment for the filtrate vs. quantitative conversion in the case of the supported catalysts 1 rGO. Preliminary results in the hot filtration test support the absence of catalytic species in solution due to the release of the molecular complex from the surface of graphene. These results suggest that the catalytic process is heterogeneous in nature and take place at the surface of graphene.

\section{Recycling studies}

In view of the good results of complex 1 in the hydrosilylation of alkynes, we decided to test the recyclability properties of the hybrid material 1-rGO in order to determine the influence of the support. ${ }^{[57]}$ Recycling experiments were carried out using phenylacetylene and dimethylphenylsilane as the model substrates. The reactions were performed using the conditions described in the general procedure (Table 1), the reaction progress was monitored by GC and the selectivity by ${ }^{1} \mathrm{H}$ NMR. After each run, the mixture was cooled down to room temperature. The solid catalyst was isolated by decantation, washed thoroughly with toluene $(3 \times 5 \mathrm{~mL})$ and used again in another run. The reaction progress profiles allow comparing the apparent reaction rates is a direct method to observe catalyst deactivation. The hydrosilylation of phenylcetylene with dimethylphenylsilane was monitored for ten runs. The reaction progress profiles reveal that the hybrid material 1-rGO was reused up to ten times (Fig. $6 a)$. The reaction progress profiles overlapped for seven runs within the experimental error $(<10 \%)$. Run 6 should be considered as an outlier because the catalyst activity is even lower than for runs 7, 8 and 9 (Figure 6a, green line with triangles). This artefact is most probably due to an experimental error in the GC measurement. In order to evaluate the mechanism of the deactivation process, the platinum content in the solution of each run was analysed by ICP-MS. The results reveal that the platinum content in the solutions corresponding to runs $1-10$ is very low. These results suggest that deactivation of the hybrid material 1 rGO is produced by catalyst manipulation during the recycling experiments. It is important to note that we have not observed a sharp catalyst deactivation. In addition, the selectivity of hydrosilylation is not affected in the recycling experiments (Fig. $6 \mathrm{~b}$ ). The $\alpha: \beta$ addition product ratio is maintained ca. $40: 60$ (at $5 \mathrm{~h}$ reaction) during all runs. Interestingly, the $\beta$-(Z) product is not observed in any run. These results suggest that the nature of the catalytic active species is preserved from batch to batch. We believe, that these results are excellent in terms of recycling especially if we consider the catalyst loading used of $0.5 \mathrm{~mol} \%$. 


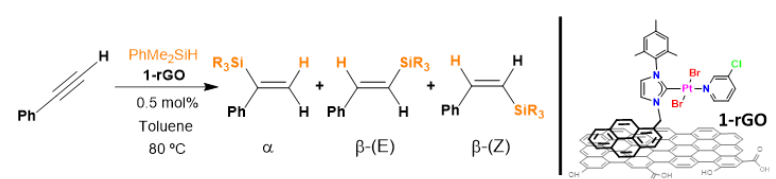

a) Activity

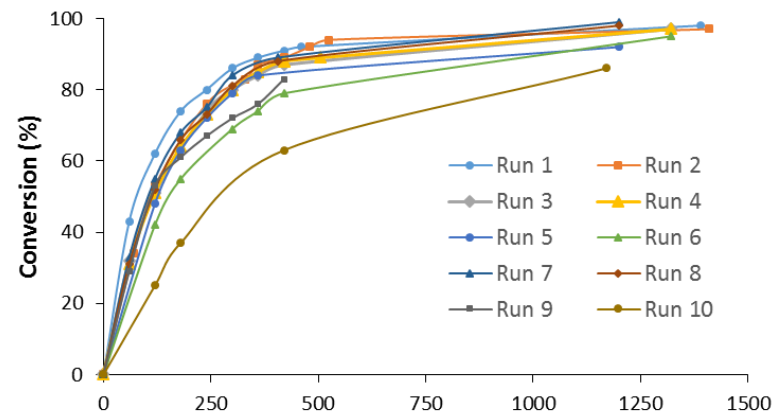

b) Selectivity Time (min)

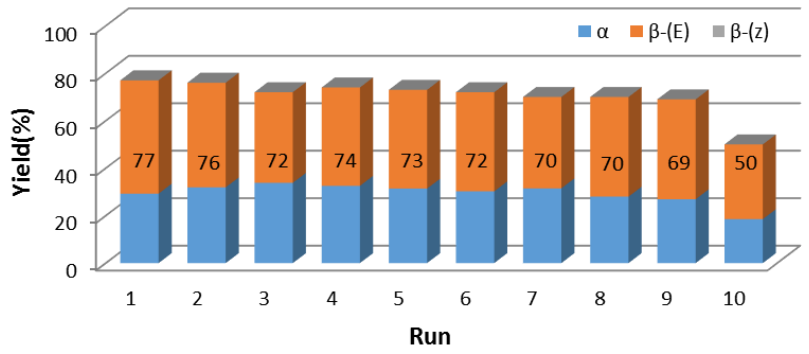

Figure 6. Recycling properties of 1-rGo in hydrosilylation. a) Activity using reaction progress profiles for runs 1 to 10 . b) Selectivity in the hydrosilylation of phenylacetylene at $5 \mathrm{~h}$ reaction. Conversions determined by GC analysis and selectivity by ${ }^{1} \mathrm{H}$ NMR.

We analysed the hybrid catalytic material 1-rGo after the recycling experiments in order to explore the changes of the support and complex 1 and get important information about the reaction mechanism and/or deactivation pathways. After ten catalytic runs, HRTEM images of the hybrid material 1-rGO showed that the morphology of the graphene is maintained after the reactions. The only difference that we noticed was the presence of more wrinkles as consequence of the usage of the hybrid material in the catalytic experiments (Fig. 7). The dark field STEM images confirmed the absence of platinum nanoparticles and the EDS elemental mapping showed the homogeneous distribution of platinum on the hybrid material 1-rGo after ten catalytic runs as it was in the initial material. These results agree with the poisoning experiments indicating that platinum nanoparticles are not involve in the hydrosilylation reaction.

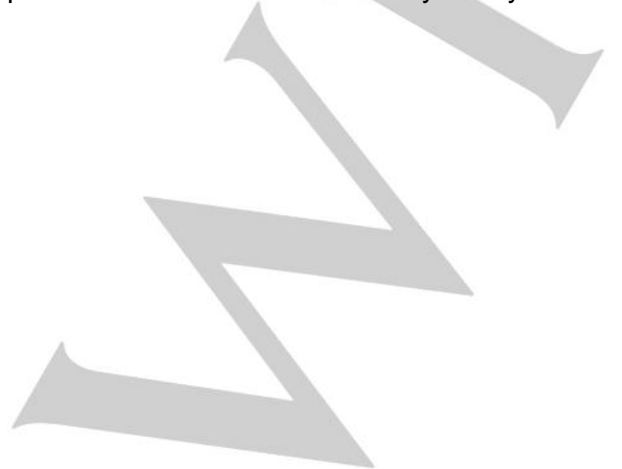

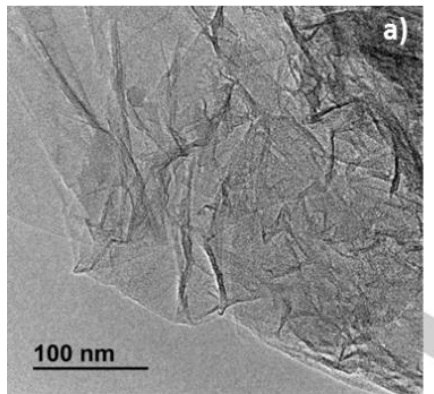
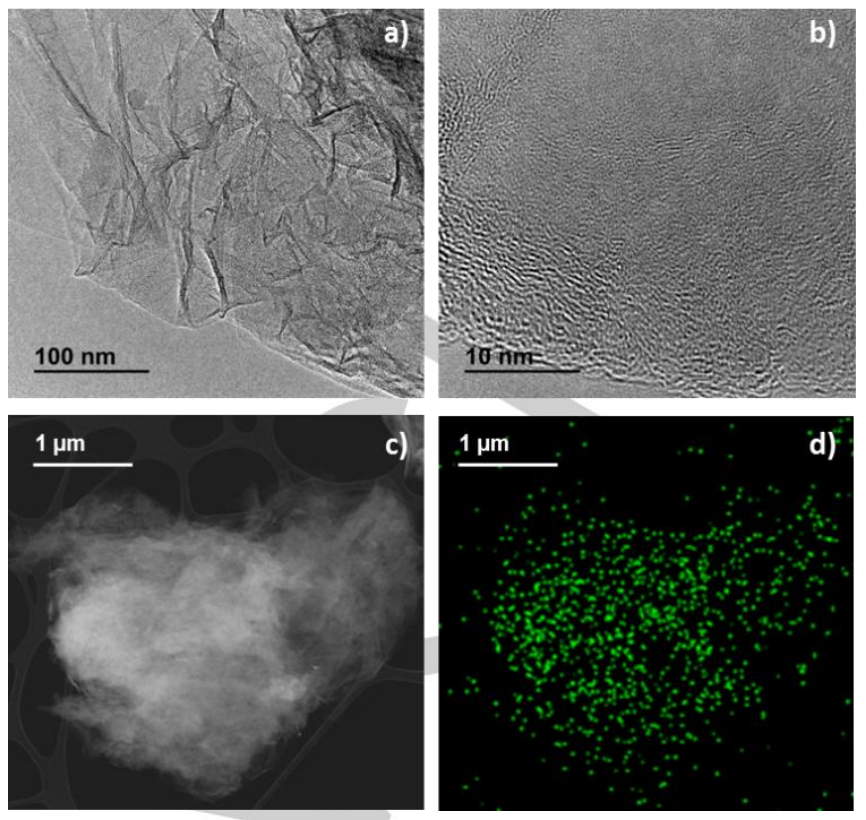

Figure 7. HRTEM images of 1-rGO at different magnifications $(a, b)$ after ten catalytic runs. STEM image showing the absence of platinum nanoparticles (c) and EDS elemental mapping (d) image shows the homogeneous distribution of platinum on the hybrid material 1-rGO after ten catalytic runs.

XPS analysis comparison of the hybrid material 1-rGO before and after ten catalytic runs (Fig. 8) displayed the expected peaks corresponding at $\mathrm{Pt} 4 \mathrm{f}, \mathrm{Br} 3 \mathrm{~d}$ and $\mathrm{N} 1 \mathrm{~s}$ at the same binding energies. The high-resolution XPS analysis for the core-level peak of Pt4f, which appears as a doublet, indicates the presence of platinum only in the +2 oxidation state. These results demonstrate that after ten catalytic runs the platinum species observed are similar to the initial ones. XPS analysis also suggests that the nature and composition of catalyst resting state should be similar to the complex 1. Thus, the hybrid material 1-rGo is a robust solid catalyst that can be reused maintaining the selectivity in hydrosilylation.

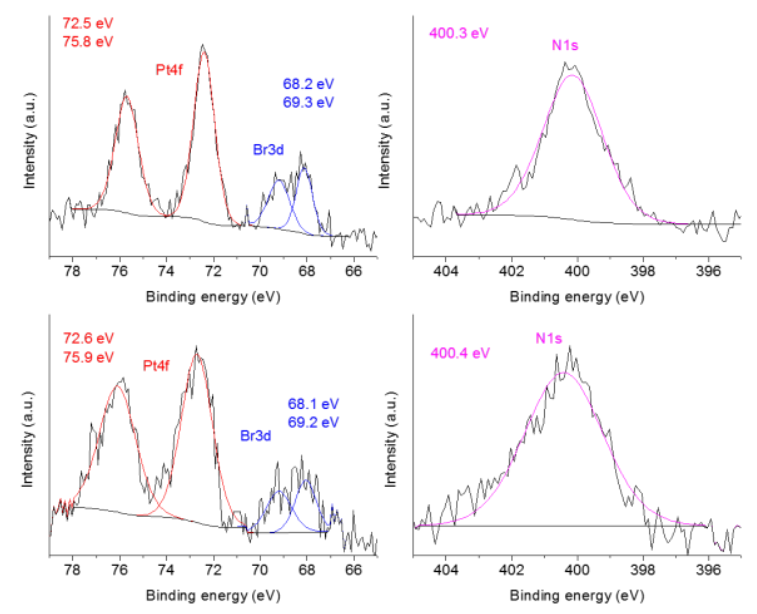

Figure 8. XPS analysis comparison of the hybrid material 1-rGo before (top) and after ten catalytic runs (bottom). 


\section{Conclusions}

A direct method for the immobilisation of metal complexes onto the surface of graphene by non-covalent interactions allows the precise control of the catalytic properties of the corresponding hybrid material. The structure of the metal complex and the properties of the support are not altered during the immobilisation process due to mild conditions used. The hybrid material contain metal sites homogeneously distributed and not only located at edges of defects. The catalytic studies with the molecular platinum complex $\mathbf{1}$ and the hybrid material 1-rGO in the hydrosilylation reaction of alkynes reveal some of the advantages of the immobilisation. The catalytic activity and stability of the molecular complex $\mathbf{1}$ is maintained when anchored onto graphene while greater reaction rates were observed. Most probably the support prevents some deactivation pathways and aid to bring in close proximity substrates with the metal sites at the surface of graphene facilitating their interaction. Nevertheless, the platinum hybrid material (1-rGO) is an efficient catalyst in hydrosilylation of alkynes allowing recycling and reuse. This work represents a clear example of the catalytic benefits observed in the immobilisation of metal complexes onto graphene. The catalytic improvement in terms of activity and stability may inspire future research in development of efficient supported catalysis.

\section{Experimental Section}

General procedures. Anhydrous solvents were dried using a solvent purification system. The imidazolium salt functionalised was prepared according to reported procedures. ${ }^{[39]}$ Nuclear magnetic resonance (NMR) spectra were recorded on Bruker spectrometers operating at 300 or 400 $\mathrm{MHz}\left({ }^{1} \mathrm{H} N M R\right)$ and 75 or $100 \mathrm{MHz}\left({ }^{13} \mathrm{C}\left\{{ }^{1} \mathrm{H}\right\} \mathrm{NMR}\right)$, respectively, and referenced to $\mathrm{SiMe}_{4}$ ( $\delta$ in ppm and $\mathrm{J}$ in Hertz). NMR spectra were recorded at room temperature with the appropriate deuterated solvent. Elemental analysis were carried out in a TruSpec Micro Series. Electrospray Mass Spectra (ESI-MS) were recorded on a MicroMass Quatro LC instrument. $\mathrm{MeOH}$ was used as mobile phase and nitrogen was used as the drying and nebulizing gas. High-resolution images of transmission electron microscopy (HRTEM) and high-angle annular dark-field (HAADF-STEM) images of the samples were obtained using a Jem-2100 LaB6 (JEOL) transmission electron microscope coupled with an INCA Energy TEM 200 (Oxford) energy dispersive X-Ray spectrometer (EDX) operating at $200 \mathrm{kV}$. Samples were prepared by drying a droplet of a $\mathrm{MeOH}$ dispersion on a carbon-coated copper grid. X-ray photoelectron spectra (XPS) were acquired on a Kratos AXIS ultra DLD spectrometer with a monochromatic Al Ka X-ray source (1486.6 eV) using a pass energy of $20 \mathrm{eV}$. To provide a precise energy calibration, the XPS binding energies were referenced to the $\mathrm{C} 1 \mathrm{~s}$ peak at $284.6 \mathrm{eV}$. GC analyses were obtained on a Shimadzu GC2010 apparatus equipped with a FID detector, and using a Teknokroma column (TRB-5MS, $30 \mathrm{~m} \times 0.25 \mathrm{~mm} \times 0,25 \mu \mathrm{m}$ ). UV-vis spectra were acquired on a Varian Cary 50 spectrophotometer.

Catalytic hydrosilylation experiments. A pyrex@ tube with a stirring bar is charged with $0.3 \mathrm{mmol}$ of alkyne, $0.31 \mathrm{mmol}$ of hydrosilane, catalyst and $1 \mathrm{~mL}$ of toluene as solvent. The tube is then introduced in a preheated 80 ${ }^{\circ} \mathrm{C}$ oil bath. Yields and conversions were determined by GC and/or ${ }^{1} \mathrm{H}$ NMR analysis using anisole or 1,3,5-trimethoxybenzene as internal standard. Recycling experiments were carried out under the same reaction conditions as described in the general procedure. After completion of each run ( $24 \mathrm{~h})$, the reaction mixture was allowed to reach room temperature and the catalyst was isolated by decantation. The solid was washed thoroughly with toluene $(3 \times 5 \mathrm{~mL})$ and toluene $(3 \times 5 \mathrm{~mL})$ and reused in the following run.
Synthesis of 1. Platinum chloride ( $200 \mathrm{mg}, 0,75 \mathrm{mmol}$ ), imidazolium salt functionalised with a pyrene-tag $(361,3 \mathrm{mg}, 0,75 \mathrm{mmol})$, potassium carbonate $(521,3 \mathrm{mg}, 3,75 \mathrm{mmol})$ and sodium bromide $(780,0 \mathrm{mg}, 7,5$ $\mathrm{mmol}$ ) were added to a Schlenk flask under nitrogen atmosphere. Then, $2,2 \mathrm{~mL}$ of 3 -chloropyridine were added, and the mixture was stirred at 80 ${ }^{\circ} \mathrm{C}$ for $43 \mathrm{~h}$. After solvent removal, the crude product was purified by column chromatography. The pure compound 1 was eluted using $\mathrm{CH}_{2} \mathrm{Cl}_{2}$ and was precipitated as a yellow solid from a mixture of $\mathrm{CH}_{2} \mathrm{Cl}_{2} /$ hexane in $69 \%$ yield. ${ }^{1} \mathrm{H}$ NMR $\left(400 \mathrm{MHz}, \mathrm{CDCl}_{3}\right): \delta 8,96\left(\mathrm{~d},{ }^{4} \mathrm{~J}_{\mathrm{H}-\mathrm{H}}=2,2 \mathrm{~Hz}, 1 \mathrm{H}, \mathrm{CH} \mathrm{Cl}-\mathrm{Py}\right)$, $8,84\left(\mathrm{~d},{ }^{3} \mathrm{~J}_{\mathrm{H}-\mathrm{H}}=5,6 \mathrm{~Hz}, 1 \mathrm{H}, \mathrm{CH}\right.$ Cl-Py $), 8,67\left(\mathrm{~d},{ }^{3} \mathrm{~J}_{\mathrm{H}-\mathrm{H}}=9,3 \mathrm{~Hz}, 1 \mathrm{H}, \mathrm{CH}_{\text {pyr }}\right), 8,21$ (m, $\left.5 \mathrm{H}, \mathrm{CH}_{\text {pyr }}\right), 8,10\left(\mathrm{~m}, 2 \mathrm{H}, \mathrm{CH}_{\text {pyr }}\right), 8,03\left(\mathrm{t},{ }^{3} \mathrm{~J}_{\mathrm{H}-\mathrm{H}}=6,3 \mathrm{~Hz}, 1 \mathrm{H}, \mathrm{CH}_{\text {pyr }}\right)$, 7,65 (ddd, ${ }^{3} J_{1} \mathrm{H}-\mathrm{H}=8,3 \mathrm{~Hz}^{4} J_{2} \mathrm{H}-\mathrm{H}=2,2 \mathrm{~Hz}{ }^{4} J_{3} \mathrm{H}-\mathrm{H}=1,3 \mathrm{~Hz}, 1 \mathrm{H}, \mathrm{CH}$ Cl-pyr), 7,18 (m, $1 \mathrm{H}, \mathrm{CH}$ cl-Pyr), 7,03 (s, 2H, CH mes), 6,69 (s, 2H, N-CH2), 6,62 (d, ${ }^{3} \mathrm{JH}_{\mathrm{H}-\mathrm{H}}$ $\left.=2,0 \mathrm{~Hz}, \mathrm{H}, \mathrm{CH}_{\text {imid }}\right), 6,53$ (d, ${ }^{3} \mathrm{~J}_{\mathrm{H}-\mathrm{H}}=2,0 \mathrm{~Hz}, 1 \mathrm{H}, \mathrm{CH}$ imid), 2,38 ( s, 3H, $\mathrm{CH}_{3}$ mes), 2,34 ( s, $6 \mathrm{H}, \mathrm{CH}_{3}$ mes). ${ }^{13} \mathrm{C}$ NMR (400 MHz, $\left.\mathrm{CDCl}_{3}\right): \delta 151,7(\mathrm{CH} \mathrm{Cl}$ Py ), 150,7 ( $\mathrm{CH}$ Cl-Py $), 148,9$ ( $\left.C_{\text {pyr }}\right), 137,5\left(C \mathrm{H}_{\text {Cl-Py }}\right), 137,4\left(C_{\text {carbene- }} \mathrm{Pt}\right)$, $136,1-123,6\left(C \mathrm{H}_{\mathrm{cl}-\mathrm{Py}}, \mathrm{C}\right.$ Cl-Py $\left., \mathrm{CH}_{\text {pyr }}, C_{\text {pyr }}, \mathrm{CH}_{\text {mes }}, C_{\text {mes }}\right), 123,3\left(\mathrm{CH}_{\text {imid }}\right)$, 120,2 ( $\left.\mathrm{CH}_{\text {imid }}\right), 53,8\left(\mathrm{~N}-\mathrm{CH}_{2}\right), 21,2\left(\mathrm{CH}_{3} \mathrm{mes}\right), 19,5\left(\mathrm{CH}_{3}\right.$ mes $)$. Electrospray MS (Cone $20 \mathrm{~V})$ (m/z, fragment): $788.0[\mathrm{M}-\mathrm{Br}]^{+}$.

Synthesis of the hybrid material 1-rGo. In a round-bottom flask were introduced $180 \mathrm{mg}$ of $\mathrm{rGO}$ and $100 \mathrm{~mL}$ of $\mathrm{CH}_{2} \mathrm{Cl}_{2}$. The suspension was introduced in ultra-sounds during 30 minutes. Then, $25 \mathrm{mg}$ of compound 1 was added to the exfoliated graphene, and the mixture was sonicated for 5 extra min. Next, the suspension was stirred at room temperature for 12 hours. The mixture was filtered and washed with $\mathrm{CH}_{2} \mathrm{Cl}_{2}(3 \times 25 \mathrm{~mL})$ obtaining a black solid (material 1-rGO). The filtrates were combined and evaporated to dryness under reduced pressure. The presence of unsupported complex 1 was analysed by ${ }^{1} \mathrm{H}$ NMR using anisole as internal standard. Integration of the characteristic signal of anisole accounts for a first indication of the complex amount deposited onto rGO. The exact amount of complex supported was determined by ICP-MS analysis. Digestion of the materials was performed in a microwave oven using nitric and hydrochloric acids (3:1). The exact amount of complex supported was determined by ICP-MS analysis. This analysis shows that the quantity of complex 1 in the material $1-$ rGO is $4.55 \%$ in weight.

\section{Acknowledgements}

The authors thank the financial support from MICIU (RTI2018098237-B-C22 and RTI2018-098903-J-I00), and Universitat Jaume I (UJI-B2018-23). A. M. thanks the Generalitat Valenciana (AICO/2015/039) for a grant. S.M. acknowledges DGA/fondos FEDER (construyendo Europa desde Aragón) for funding the research group Platón (E31_17R). The authors are very grateful to the 'Servei Central d'Instrumentació Científica (SCIC)' of the Universitat Jaume I as well as to Dr. G. Antorrena for technical support in the XPS studies.

\section{Notes}

CCDC1966283 contains the supplementary crystallographic data for this paper. These data are provided free of charge by The Cambridge Crystallographic Data Centre.

\section{Conflict of interest}

The authors declare no conflict of interest.

Keywords: Supported catalysis • hydrosilylation • graphene • Platinum • N-heterocyclic carbenes $(\mathrm{NHC})$ 
[1] B. Marciniec, H. Maciejewski, C. Pietraszuk, P. Pawluć, in Appl. Homog. Catal. with Organomet. Compd., Wiley, 2017, pp. 569-620.

[2] B. Marciniec, in Hydrosilylation, Springer Netherlands, Dordrecht, 2008 pp. 53-86.

[3] L. N. Lewis, J. Stein, Y. Gao, R. E. Colborn, G. Hutchins, Platin. Matals Rev. 1997, 41, 66-75.

[4] T. K. Meister, K. Riener, P. Gigler, J. Stohrer, W. A. Herrmann, F. E. Kühn, ACS Catal. 2016, 6, 1274-1284.

[5] Y. Nakajima, S. Shimada, RSC Adv. 2015, 5, 20603-20616.

[6] D. Troegel, J. Stohrer, Coord. Chem. Rev. 2011, 255, 1440-1459.

[7] B. Karstedt, Gen. Electr. Company, U.S. Pat. No. 3775452A 1973.

[8] J. L. Speier, J. A. Webster, G. H. Barnes, J. Am. Chem. Soc. 1957, 79, 974-979.

[9] I. E. Markó, S. Stérin, O. Buisine, G. Mignani, P. Branlard, B. Tinant, J.P. Declercq, Science 2002, 298, 204-206.

[10] G. Berthon-Gelloz, O. Buisine, J. F. Brière, G. Michaud, S. Stérin, G. Mignani, B. Tinant, J. P. Declercq, D. Chapon, I. E. Markó, J. Organomet Chem. 2005, 690, 6156-6168.

[11] S. Dierick, I. E. Markó, N-Heterocyclic Carbenes Eff. Tools Organomet. Synth. 2014, 9783527334, 111-150.

[12] S. Dierick, E. Vercruysse, G. Berthon-Gelloz, I. E. Markõ, Chem. Eur. J. 2015, 21, 17073-17078.

[13] R. H. Crabtree, Chem. Rev. 2012, 112, 1536-1554.

[14] M. A. Taige, S. Ahrens, T. Strassner, J. Organomet. Chem. 2011, 696, 2918-2927.

[15] E. Bolbat, K. Suarez-Alcantara, S. E. Canton, O. F. Wendt, Inorg. Chim. Acta 2016, 445, 129-133.

[16] R. S. Chay, B. G. M. Rocha, A. J. L. Pombeiro, V. Y. Kukushkin, K. V. Luzyanin, ACS Omega 2018, 3, 863-871.

[17] P. Żak, M. Bołt, M. Kubicki, C. Pietraszuk, Dalton Trans. 2018, 47, 1903 1910.

[18] G. F. Silbestri, J. C. Flores, E. de Jesús, Organometallics 2012, 31, 3355-3360.

[19] R. Ye, J. Zhao, B. B. Wickemeyer, F. D. Toste, G. A. Somorjai, Nat. Catal. 2018, 1, 318-325.

[20] R. Zhong, A. C. Lindhorst, F. J. Groche, F. E. Kühn, Chem. Rev. 2017, 117, 1970-2058.

[21] W. Wang, L. Cui, P. Sun, L. Shi, C. Yue, F. Li, Chem. Rev. 2018, 118 , 9843-9929.

[22] M. Benaglia, Ed., Recoverable and Recyclable Catalysts, John Wiley \& Sons, Ltd, Chichester, UK, 2009.

[23] M. R. Axet, O. Dechy-Cabaret, J. Durand, M. Gouygou, P. Serp, Coord. Chem. Rev. 2016, 308, 236-345.

[24] M. R. Axet, J. Durand, M. Gouygou, P. Serp, Surface Coordination Chemistry on Graphene and Two-Dimensional Carbon Materials for Well-Defined Single Atom Supported Catalysts, Elsevier Inc., 2019.

[25] J. A. Gladysz, Pure Appl. Chem. 2001, 73, 1319-1324.

[26] C. Xu, B. Huang, T. Yan, M. Cai, Green Chem. 2018, 20, 391-397.

[27] Y. Naganawa, Y. Maegawa, H. Guo, S. S. Gholap, S. Tanaka, K. Sato, S. Inagaki, Y. Nakajima, Dalton Trans. 2019, 48, 5534-5540.

[28] L. Chen, I. S. Ali, G. E. Sterbinsky, J. T. L. Gamler, S. E. Skrabalak, S. L. Tait, ChemCatChem 2019, 11, 2843-2854.

[29] S. Sabater, J. A. Mata, in Non-Covalent Interact. Synth. Des. New Compd., John Wiley \& Sons, Inc, Hoboken, NJ, 2016, pp. 313-326.

[30] S. Sabater, J. A. Mata, E. Peris, ACS Catal. 2014, 4, 2038-2047.

[31] V. Georgakilas, M. Otyepka, A. B. Bourlinos, V. Chandra, N. Kim, K. C. Kemp, P. Hobza, R. Zboril, K. S. Kim, Chem. Rev. 2012, 112, 6156-6214.

[32] V. Georgakilas, J. N. Tiwari, K. C. Kemp, J. A. Perman, A. B. Bourlinos, K. S. Kim, R. Zboril, Chem. Rev. 2016, 116, 5464-5519.

[33] T. K. Maishal, J. Alauzun, J.-M. Basset, C. Copéret, R. J. P. Corriu, E. Jeanneau, A. Mehdi, C. Reyé, L. Veyre, C. Thieuleux, Angew. Chem. Int Ed. 2008, 47, 8654-8656.

[34] M. K. Samantaray, J. Alauzun, D. Gajan, S. Kavitake, A. Mehdi, L. Veyre, M. Lelli, A. Lesage, L. Emsley, C. Copéret, et al., J. Am. Chem. Soc. 2013, 135, 3193-3199.

[35] C. Copéret, A. Comas-Vives, M. P. Conley, D. P. Estes, A. Fedorov, V. Mougel, H. Nagae, F. Núñez-Zarur, P. A. Zhizhko, Chem. Rev. 2016, 116, 323-421.

[36] C. Valente, S. Çalimsiz, K. H. Hoi, D. Mallik, M. Sayah, M. G. Organ,
Angew. Chem. Int. Ed. 2012, 51, 3314-3332.

[37] M. Bouché, A. Bonnefont, T. Achard, S. Bellemin-Laponnaz, Dalton Trans. 2018, 47, 11491-11502.

[38] M. Bouché, G. Dahm, M. Wantz, S. Fournel, T. Achard, S. BelleminLaponnaz, Dalton Trans. 2016, 45,11362-11368.

[39] D. Ventura-Espinosa, S. Sabater, J. A. Mata, J. Catal. 2017, 352, 498504.

[40] O. V. Dolomanov, L. J. Bourhis, R. J. Gildea, J. A. K. Howard, H. Puschmann, J. Appl. Crystallogr. 2009, 42, 339-341.

[41] S. Sabater, J. A. Mata, E. Peris, Organometallics 2015, 34, 1186-1190.

[42] J. A. Mata, E. Peris, S. Sabater, Soporte de Catalizadores En Derivados de Grafeno. Spain Pat. No P201331680, 2015.

[43] M. Peuckert, F. P. Coenen, H. P. Bonzel, Electrochim. Acta 1984, 29 1305-1314.

[44] J. M. Richardson, C. W. Jones, Adv. Synth. Catal. 2006, 348, 1207-1216.

[45] P. Foley, R. DiCosimo, G. M. Whitesides, J. Am. Chem. Soc. 1980, 102 6713-6725

[46] R. H. Crabtree, Chem. Rev. 2015, 115, 127-150.

[47] D. Ventura-Espinosa, A. Carretero-Cerdán, M. Baya, H. García, J. A. Mata, Chem. Eur. J. 2017, 23, 10815-10821.

[48] D. Ventura-Espinosa, S. Sabater, A. Carretero-Cerdán, M. Baya, J. A. Mata, ACS Catal. 2018, 8, 2558-2566.

[49] A. Mollar-Cuni, D. Ventura-Espinosa, S. Martín, Á. Mayoral, P. Borja, J. A. Mata, ACS Omega 2018, 3, 15217-15228.

[50] D. Ventura-Espinosa, C. Vicent, M. Baya, J. A. Mata, Catal. Sci. Technol. 2016, 6, 8024-8035.

[51] D. Ventura-Espinosa, A. Marzá-Beltrán, J. A. Mata, Chem. Eur. J. 2016 22, 17758-17766.

[52] P. Ballestin, D. Ventura-Espinosa, S. Martín, A. Caballero, J. A. Mata, P. J. Pérez, Chem. - A Eur. J. 2019, 25, 9534-9539.

[53] D. Ventura-Espinosa, S. Martín, J. A. Mata, J. Catal. 2019, 375, 419426.

[54] C. Vriamont, M. Devillers, O. Riant, S. Hermans, Chem. Eur. J. 2013, 19, 12009-12017.

[55] E. Bayram, J. C. Linehan, J. L. Fulton, J. a S. Roberts, N. K. Szymczak, T. D. Smurthwaite, S. Özkar, M. Balasubramanian, R. G. Finke, J. Am. Chem. Soc. 2011, 133, 18889-18902.

[56] N. T. S. Phan, M. Van Der Sluys, C. W. Jones, Adv. Synth. Catal. 2006, 348, 609-679.

[57] M. P. Conley, C. Copéret, Top. Catal. 2014, 57, 843-851. 


\section{Entry for the Table of Contents}

\section{Supported Catalysis}

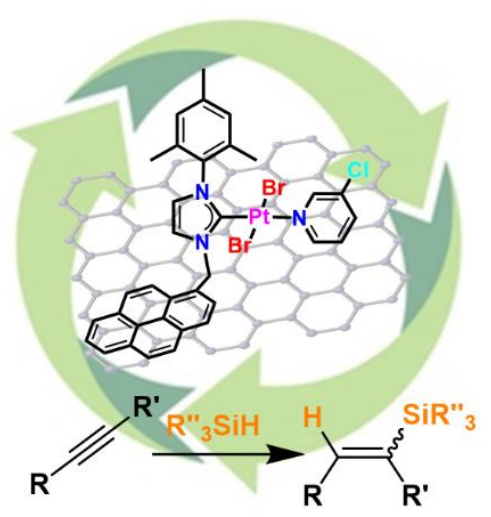

Development of a hybrid material composed by a well-defined platinum complex and graphene is described. The immobilization is achieved in a single-step by functionalization with a pyrene-tag and thanks to the formation of $\pi$-staking interactions. This methodology paves the way for a direct access of solid catalysts that allow catalyst recycling and improve catalyst efficiency. 